\title{
ARQUITETURA ESCOLAR E GÊNERO: SEPARAÇÕES E MISTURAS NA TRANSIÇÃO DA EDUCAÇÃO SEPARADA PARA A MISTA
}

\author{
Korina Aparecida Teixeira Ferreira da Costa \\ Universidade do Oeste Paulista - UNOESTE, Programa de Pós Graduação em Educação, Presidente Prudente, SP. E- \\ mail: korina.arq@gmail.com
}

\begin{abstract}
RESUMO
Este trabalho, insere-se na linha de pesquisa "Instituição educacional: organização e gestão", do Mestrado em Educação da Unoeste, cuja pesquisa, de natureza qualitativa e caracterizada como estudo de caso, teve como objeto de estudo a arquitetura escolar em suas interfaces com as relações de gênero, conforme estudo realizado na escola João Franco de Godoy, em Presidente Prudente, no período entre as décadas de 1950 e 1970, momento que coincide com a construção de uma nova edificação para a escola, cujas formas Ihe concedem o apelido de escola Navio, como ficará mais conhecida, apresentando uma transição da educação separada para a mista. Onde objetiva-se a averiguação de como as condicionantes espaciais, de preceito moderno e as práticas educacionais, articularam os liames sociais e culturais de poder como um todo e em especial no que diz respeito às relações de gênero.
\end{abstract}

Palavras-chave: Arquitetura Escolar, Gênero, Educação Mista

\section{SCHOOL AND GENDER ARCHITECTURE: SEPARATIONS AND MIXTURES IN THE TRANSITION FROM SEPARATE TO MIXED EDUCATION}

\begin{abstract}
This work is part of the research line "Educational Institution: Organization and Management", of the Master's Degree in Education of Unoeste, whose research, of a qualitative nature and characterized as a case study, had as object of study the school architecture in its interfaces with gender relations, according to a study carried out at the João Franco de Godou school in Presidente Prudente between the 1950s and 1970s, coinciding with the construction of a new building for the school, whose forms grant it the nickname of ship school, as it will become better known, presenting a transition from separate to mixed education. The objective is to investigate how spatial constraints, modern precepts and educational practices have articulated the social and cultural ties of power as a whole and especially with regard to gender relations.
\end{abstract}

Keywords: School Architecture, Gender, Mixed Education 


\section{INTRODUÇÃO}

A presente pesquisa visou analisar a arquitetura escolar no que diz respeito às relações de gênero, conforme apresentados na Escola João Franco de Godoy, mais conhecida como escola "Navio", no período entre as décadas de 1950 e 1970, época na qual é construída a nova edificação para abrigar as atividades da escola, que passa a oferecer exclusivamente o modelo misto de ensino, visando cumprir os direcionamentos pedagógicos do Estado de São Paulo, para a co-educação.

Muitos são os estudiosos que defendem a importância e a influência que a arquitetura tem na vida e comportamento das pessoas e tal fenômeno se intensifica no campo educacional, devido ao tempo em que alunos, professores e funcionários passam na escola. Com a finalidade de estudar tal fenômeno, estudou-se a Escola Navio, justamente no período que a antiga edificação de madeira, foi substituída pela nova e moderna escola, que possuía características da Arquitetura Brutalista.

Cuja análise da arquitetura escolar, concentra-se na relação que a mesma tem com a abordagem de ensino adotada levando em consideração os cenários sociais, culturais e políticos da referida época para o campo educacional. Tal discussão aproxima-se do cenário político vivenciado no Brasil, já que a mesma foi inaugurada, dois anos antes do golpe militar de 1964, quando a nova escola, passou a abrigar meninos e meninas em uma mesma sala de aula.

\section{METODOLOGIA}

Trata-se de uma pesquisa qualitativa do tipo estudo de caso, que para Lüdke e Andre (1986), deve ser iniciado por uma fundamentação teórica, para que o pesquisador possa se manter atento aos fenômenos relevantes no momento da coleta de dados e afinamento com o objeto de estudo, a serem feitos de forma contextualizada. Foram feitos estudos documentais e levantamentos in loco. Aplicou-se uma pesquisa semiestruturada com ex-alunos e ex-alunas da escola e depois usou-se o método de triangulação de dados de Minayo (2007), para se chegar às categorias de análise e se estabelecer os critérios de análise.

\section{RESULTADOS}

As escola brasileiras mudaram muito tipológica e metodologicamente, desde o período colonial até a república, cujos primeiros modelos foram os Grupos Escolares e Escolas Normais, na passagem dentre o século XIX para o XX, as edificações escolares demandavam atender as aspirações das classes sociais mais abastadas, onde geralmente eram voltadas para praças e remetiam os conceitos de ordem e poder política. (KOWALTOWSKI, 2011).

Com o governo de Juscelino Kubistchek em 1950, a educação passou a ser um símbolo de modernidade, no qual a arquitetura escolar passou a apresentar formas geométricas mais simples, pátios internos e concreto aparente (KOWALTOWSKI, 2011). Entre as décadas de 1950 e 1970, em uma época em que o discurso educacional defendido no Estado de São Paulo visava uma política pedagógica de coeducação, ou seja, que além da educação mista, reconhecia a necessidade de uma política que promovesse novas formas de pensar e agir democraticamente, respeitando as diferenças existentes entre meninos e meninas, foi que a escola João Franco de Godoy teve seu primeiro edifício construído de madeira, substituído por um segundo de características modernistas.

Desta forma, conforme Viñao Frago (1995) e Escolano (2001), em meados do século XX, as novas edificações escolares passam a adquirir características modernas, visando atender às novas metodologias educacionais, que além de sua forma pura e geométrica, não ornamental e mais econômica, das suas edificações, estas buscam também tornarem-se promotoras da integração e/ou segregação entre os seus usuários. 
Neste sentido, Teixeira (apud KOWALTOWSKI, 2000, p. 157), acrescenta que "[...] sem instalações adequadas não poderia haver trabalho educativo, e o prédio, base física e preliminar para qualquer programa educacional, torna-se indispensável para a realização de todos os demais planos de ensino propriamente dito". Carvalho (2000), acrescenta que Anísio Teixeira idealizava uma escola voltada para a preparação do indivíduo para o trabalho e para a vida e que se distanciasse de um local apenas de se aprender a ler e escrever, para tanto deveriam ter espaços como o pátio, a sala de leitura, a biblioteca e o auditório (KOWALTOLWSKI, 2011).

Investigar o processo de instalação da escola, a caracterização e as utilização do espaço físico (elementos arquitetônicos do prédio, sua implantação no terreno, seu entorno e acabamento), o espaço do poder (diretoria, secretaria, sala dos professores), a organização do uso do tempo, a seleção dos conteúdos escolares, a legislação, as normas e a administração da escola. Estas categorias permitem traçar um relato da escola com seus atores, aspectos de sua organização, seu cotidiano, seus rituais, sua cultura e seu significado para aquela sociedade. (BUFFA, 2002, p. 27).

Guacira Lopes Louro (2003, p. 23), por sua vez, faz ver que os edifícios atuam como produtores de formação das identidades masculinas e femininas dos sujeitos que os frequentam, ocasionando a reprodução das diferenças de "[...] gênero, etnia, classe ou/e sexualidade". Os mesmos apresentam áreas mais ou menos usadas por cada um deles, promovendo as condicionantes de integração ou segregação social. Pois, "a escola informa e produz significados que podem vir a se transformar em estigmas que limitam as possibilidades de inclusão dos indivíduos na escola e afetam negativamente suas condições de aprendizagem" (LOURO, 2003, p. 23).

Cujas discussões de gênero estão diretamente associadas à existência ou não de coeducação, entendendo-se que a educação mista não basta para que ela aconteça. Tal ideia engloba mais condicionantes que a simples divisão espacial entre meninos e meninas, em ambientes escolares, para Auad (2002-2003), a escola mista, por si só não é suficiente, ela representa uma condição para a coeducação, que só pode realmente se instaurar se as práticas pedagógicas realmente permitirem relações de aprendizagem e comportamento pautados em equidade, não sendo inerente apenas à escola, mas têm nela a ferramenta de exercício para as práticas que possibilitam ou dificultam a autonomia dos estudantes.

\section{DISCUSSÃO}

A nova edificação da Escola João Franco de Godoy, representava o acompanhamento às correntes mais modernas da arquitetura da época, conforme os preceitos do Movimento Moderno em Arquitetura, apresentados conforme as propostas constantes do Brutalismo Paulista, observado através de seus aspectos de racionalismo construtivo, nas relações entre dimensionamento, funcionalidade e características técnico-estruturais, na simplicidade formal e na valorização do elemento construtivo, facilmente percebida através das voluptuosas estruturas em concreto aparente (FRAMPTON, 2008; BENEVOLO, 2009).

A escola certamente cumpria o papel de modernidade buscada, o que em muito se relaciona à sua forma geométrica triangular, que se destacava na paisagem do bairro e assim, chamou a atenção da população, que na busca de lhe atribuir um valor figurativo, cujas arestas, vistas pelos transeuntes, Ihes promoveu a relação a um barco, assim, passaram a chamá-la pelo apelido de escola "Navio", tal formato chamou muito a atenção, pois distanciava-se de uma modelagem tradicional e rígida, cujas formas transmitem fluidez e leveza.

Ao assumir sua posição enquanto abrigo para as atividade humanas, a arquitetura responsabiliza-se em atender as buscas de seus usuários em qualquer período vivido, conforme uma tecnologia para edifica-la e através de um referencial tipológico e estético, mas nada disso seria representativo, sem o que Certeau (2012), chama de lugar, concebido como a instituição, o 
ensino e os direcionamentos definidos na escala das estratégias, cuja materialidade se apresenta através de suas paredes, salas, escadas, janelas, quadros-negros, cores, muros, dentre outros elementos construtivos, como um código de linguagem a ser decifrado e, assim, tornando-se o que chamamos de espaço, evidenciado pelas vivências diárias dos usuários, correspondentes às estratégias e táticas por eles desenvolvidos.

Fernandes (2005), complementa dizendo que era costumeiro na arquitetura escola transmitir uma mensagem de controle, expresso pelo habitual comportamento regido pelas punições e castigos, o que Foucault (2006), definia como espaços de vigiar e punir. Desta forma, em geral, a presente análise busca-se em Foucault (2006), os aspectos de disciplinamento e em Certeau (2012), as estratégias e táticas de transgressão, assim como dos exercícios de poder executados através de espaços específicos, que através da edificação da escola impôs-se aos seus usuários, mas especificamente seus alunos e alunas, o que se evidencia através da apropriação de determinadas porções da edificação por grupos específicos.

Com a sua construção em concreto armado aparente, a estrutura modular da escola Navio, apresenta elementos para proporcionar uma planta livre, materializada através de seu volume triangular, que se ergue do solo através de pilotis, conferindo-lhe leveza visual e convidando, alunos, professores, funcionários e sociedade a adentrarem, seu pátio coberto, que se liga com o pavimento superior através de duas escadas laterais. Na sua porção central há um jardim, que pode ser contemplado também do corredor existente no andar superior, logo à frente das salas de aula, estabelecendo uma continuidade entre os diferentes lances da edificação, fatores estes que a apresentam como portadora das condições de aplicabilidade das novas pedagogias.

Comportamentos que a ordenação dos elementos formais, estruturais e espaciais desenvolvido para a escola Navio, deixaram para traz, pois traduziam os novos ideais pedagógicos de democracia, liberdade de expressão e o compartilhamento de suas áreas por todos, independentemente da do gênero, porém a mesma passa ao enfrentamento de direcionamento opostos, apenas dois anos após sua inauguração, já que em 1964, houve o início da ditadura militar, que promoveu outras resoluções para as pedagogias de ensino.

Partindo da compreensão de que uma escola é a soma de seus elementos formais, funcionais, simbólicos, pedagógicos e comportamentais, e que estes são os direcionadores de seus aspectos de uso, é que se pode promover a análise da escola Navio, através dos usos generificados pelos seus espaços. Tal análise advém de pontos específicos para o uso, ocupação e apropriação dos lugares, por meninos e meninas. Sob tal perspectiva, foram encontrados e tematizados os lugares mais mencionados pelos entrevistados, sendo eles a sala de aula, o pátio e a escada.

Assim como suas ocupações em momentos específicos do dia-a-dia escolar, sendo eles, no que diz respeito ao pátio, destaca-se a entrada na escola, a formação da fila, a exaltação do patriotismo, momentos de muita formalidade e de postura respeitosa, já os comportamentos desenvolvidos no horário do recreio, permitia-se menos formalidade e até as brincadeiras, porém havia uma evidente segmentação de gênero, sendo permitido aos meninos circular e até mesmo correr livremente pelas áreas livres, quanto às meninas, costumeiramente encontravam-se sentadas, ou reunidas em pequenos grupos para conversar.

As escadas despontam como importante local de determinação de poder, já que através das mesmas pode-se estabelecer o controle nas relações entre o pavimento térreo e o superior, onde se encontravam as salas de aula, os relatos das entrevistas evidenciaram que os meninos costumavam sentar-se nos degraus e até mesmo pular e correr de cima a baixo, assim como se concentrar no vão abaixo do piso para brincar. Já as meninas entravam em contato com a escada apenas no momento de subir para a sala de aula.

A sala de aula, representava o local do saber, portanto os alunos e alunas, deveriam ter um comportamento respeitoso dentro delas, sendo os espaços que melhor concretizam a 
mensagem abstrata da aquisição de conhecimento. As carteiras eram posicionadas ordenadamente em fila, primeiramente com os alunos agrupados em duplas e alguns anos depois, eles passaram a possuir cadeiras e carteiras individuais.

Onde muitas vezes os meninos mais inquietos eram posicionados junto à mesa da professora e perto da porta era comum haver uma menina sentada, o que representa uma setorização de gênero, já que o controle maior deveria estar voltado ao comportamento dos meninos e em contraponto era esperado das meninas mais disciplina em seu cotidiano, elas eram constantemente cobradas para ter boa letra e postura educada, assim como empenho para as atividades manuais e de língua portuguesa e aos meninos permitia-se menos capricho, porém esperava-se destaque na matemática e ciências.

Observações estas evidenciam que o sujeito é um produto da introjeção de códigos sociais e culturais, reafirmando o que pensam os estudiosos e estudiosas das condicionantes de gênero, a respeito das masculinidades e feminilidades serem socialmente produzidas, o que no caso da escola Navio, que foi idealizada arquitetonicamente para abrigar a equidade e que na prática foi usada para dar continuidade às práticas tradicionais e da perpetuação do ser e fazer específicos para meninos e meninas.

\section{CONCLUSÃO}

Esmiuçar tal universo foi algo promotor de um grande desenvolvimento pessoal, porém, a significância da presente busca representa a procura pela discussão das relações pouco tratadas e igualmente pouco compreendidas, mas de extrema significância para a construção da história da educação brasileira. Torna-se relevante e singular tratar o tema pelo viés do gênero e suas concatenações com os usos e apropriações do espaço arquitetônico. Mais particularmente constata-se as relações de poder existentes no cotidiano escolar, indicando para as apropriações e/ou resistências ao controle e disciplinamento para os papéis normativos de gênero pelos sujeitos que frequentavam a escola.

Muitos acontecimentos, valores socioculturais e práticas pedagógicas aconteceram entre o período recortado pela pesquisa e os dias atuais. Hoje a escola é de caráter público-municipal e recebe crianças do Ensino Fundamental I, nos períodos matutino e vespertino. A escola ganhou muros bastantes fechados, que se destacam mais que a própria edificação, que deixou de possuir o destaque no bairro, que possuía no momento da sua construção, recebeu pintura e um pátio coberto, que não dialogam com as propostas brutalistas originais, estando bastante descaracterizada.

\section{REFERÊNCIAS}

AUAD, D. Educação para a democracia e co-educação: apontamentos a partir da categoria gênero. Revista USP. São Paulo, n.56, p. 136-143, dez./fev. 2003-2003.

BENEVOLO, L. História da arquitetura moderna. São Paulo: Perspectiva, 2009.

BUFFA, E. História e filosofia das instituições escolares. In: ARAÚJO, S.; GATTI JUNIOR, D. (Orgs.) Novos temas em história da educação brasileira: instituições escolares e educação na imprensa. Campinas: Autores Associados; Uberlândia: EDUFU, 2002.

CARVALHO, M. Reformas na Instrução Pública. In: LOPES, M; FARIA FILHO, M.; VEIGA, G. (Orgs.). 500 anos de Educação no Brasil. Belo Horizonte: Autêtica, 2000.

CERTEAU, M. A invenção do cotidiano: antes de fazer. 19. ed. Tradução de Ephraim Ferreira Alves. Petrópolis, RJ: Vozes, 2012. 
ESCOLANO, A. Arquitetura como programa: espaço-escola e currículo. In: VIÑAO FRAGO, A.;

ESCOLANO, A. Currículo, espaço e subjetividade: a arquitetura como programa. 2.ed. Rio de Janeiro DP\&A, 2001.

FERNANDES, R. Cultura de Escola: entre as coisas e a memória. Proposições. v. 16. n. 1 (46), jan./abr., 2005.

FOUCAULT, M. Vigiar e punir: o nascimento da prisão. 31.ed. Petrópolis: Vozes, 2006.

FRAMPTON, K. História crítica da arquitetura moderna. 4.ed. São Paulo: Martins Fontes, 2008.

KOWALTOWSKI, D. Anísio Teixeira e a arquitetura escolar: planejando escolas, construindo sonhos. Revista da FAEEBA, Salvador, n. 13, p. 151-160, jan/jun. 2000.

Arquitetura escolar: o projeto do ambiente de ensino. São Paulo: Oficina de textos, 2011.

LOURO, L. Gênero, sexualidade e educação. Uma nova perspectiva pós-estruturalista. Petrópolis: Vozes, 2003.

LÜDKE, M. ANDRÉ, M. Pesquisa em educação: Abordagens qualitativas. São Paulo: E.P.U., 1986.

MINAYO, S. Introdução. In: MYNAYO, S.; ASSIS, G.; SOUZA, R. (Orgs.). Avaliação por triangulação de métodos: abordagem de programas sociais. Rio de Janeiro: Fiocruz, 2007.

VIÑAO FRAGO, A. Historia de la educación y historia cultural: possibilidade, problemas, cuestiones. Revista Brasileira de Educação. Campinas, SP, n.0, p. 63-82. set./out./nov./dez. 1995. 